\title{
GRADUAL-RANDOMIZED MODEL OF POWERED ROOF SUPPORTS WORKING CYCLE
}

\author{
Marcin Michalak \\ Institute of Informatics, Silesian University of Technology, Gliwice, Poland \\ Marcin.Michalakepolsl.pl
}

\begin{abstract}
Due to increasing efforts on saving natural environment - observed also as an increase of renewable resource energy production - a traditional underground coal mining introduces new technologies of machine diagnosis to assure this process to be more safe and generate less pollution. Also the economic reasons influence development of monitoring systems. Among the most important elements of underground coal mining are longwall systems, whose essential parts are powered roof supports. Avoiding failures and limitation of power consumption should result in more ecological underground coal mining. The paper presents the new model of powered roof support single unit work. The better understanding of its operating and the possibility to generate data describing a proper and improper operation will help to develop monitoring and diagnosis systems.
\end{abstract}

\section{KEYWORDS}

Machine Modelling, Longwall Systems, Machine Diagnosis, Coal Mining, Underground Mining

\section{INTRODUCTION}

Despite increasing significance of renewable resource energy production, coal based energy production still remains a meaningful part of industry of many countries (just to mention Poland and Germany [1][2]). Due to this fact problems of coal mining still have a global meaning.

Among many methods of coal mining the most common technology is longwall mining. In this technology a coal deposit is drawn out in the place called a longwall. A typical longwall is several hundred meters long and consists of longwall shearer which tears off the coal from the rock, a conveyor which transports the output out of the wall and the powered roof support whose main task is to protect the people and the equipment of the falling rocks from the roof. A simple scheme of a longwall complex is presented on the Fig. 1.Almost all of longwall complex components are points of interest of monitoring and diagnostic systems and scientific research $[3][4][5][6][7]$. 
A proper operation of a whole longwall complex, including the powered roof support, becomes an essential issue from the both the safety considerations and economical aspects. The safety of the operation depends on the various factors: natural, technical and human. It is expected from the monitoring and diagnostic systems to detect and recognize a proper machine operation but also - what is probably even more important - improper operation and some defects and failures. It is usually very hard or even impossible to gather the data describing all possible situations, data that will become a training set for a monitoring system. Therefore it is demanded to know the characteristics of proper and improper device operations, characteristics of effects of failures and include them in the model of machine. If the model of the machine work is ready, it is possible to generate an artificial data and put it into the diagnostic system as patterns.

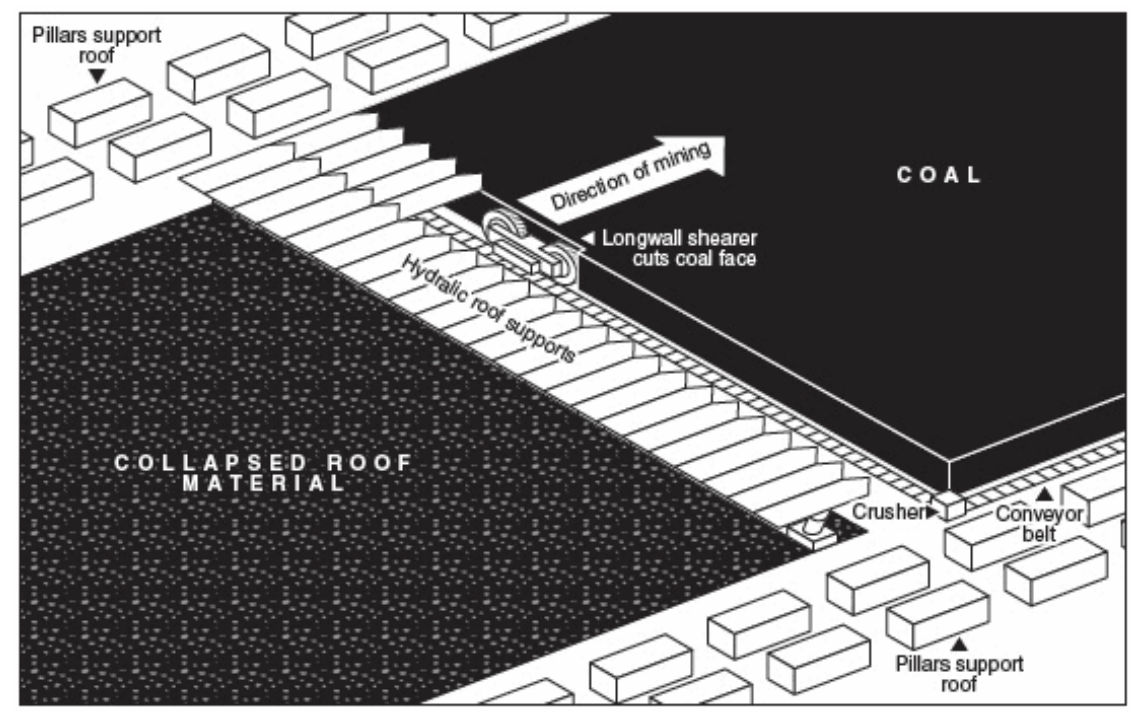

Fig. 1 Longwall complex scheme (http://www.changingcoast.org.uk/).

In this paper extension of the model of single powered roof support work is presented. The paper is organized as follows: it starts from the brief description of a system of powered roof support its structure and typical work characteristic. Then a previous simple model of modelling a proper unit working cycle is described - the decomposition of a working cycle and mathematical model of each phase. Afterwards a modified version of the model is explained, assuring more stable and reliable values after the second phase of the cycle and more authentic characteristic of a gradual leg pressure increase. The paper ends with some results of modelling and final conclusions and goals of further works.

\section{POWERED ROOF SUPPORTS}

Powered roof supports are essential element of the longwall complex as their main role is to prop the rock over workers and machines (Fig. 2). This implies the need of a proper roof supports operation and permanent observation of operating conditions and diagnostic state of separate powered roof support units. For better understanding of these aspects in this section a brief description of structure and typical working cycle of a single unit of powered roof support will be presented. 


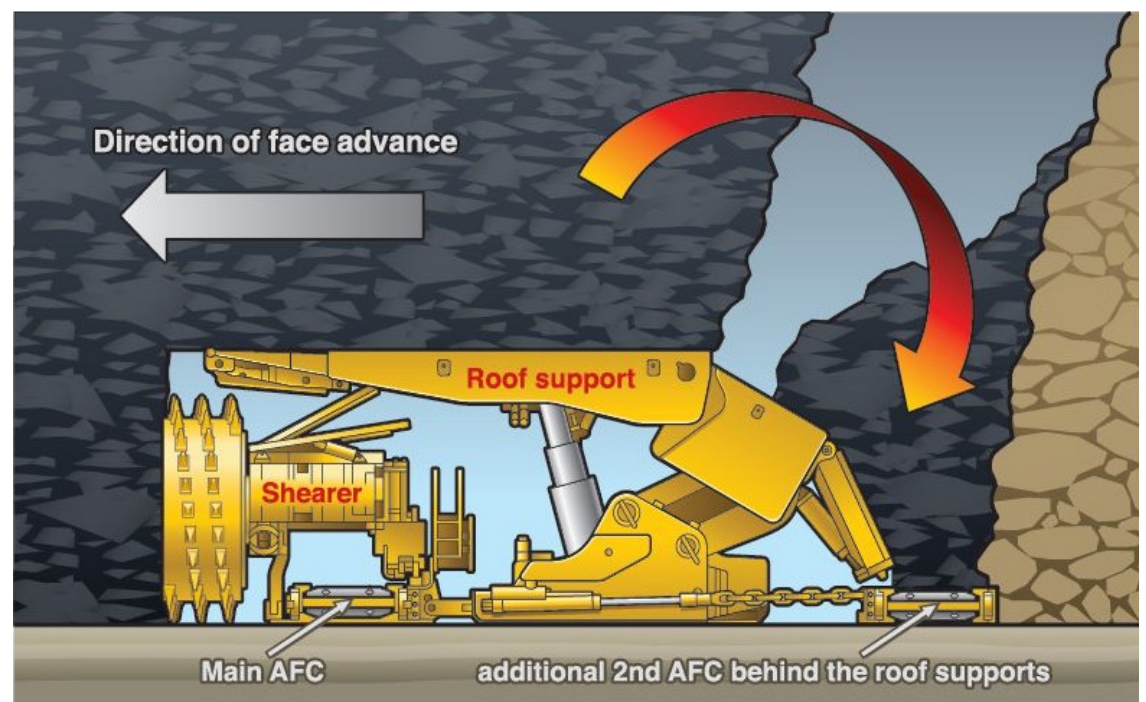

Fig. 2 The profile of a single unit in the longwall (www.mining.com).

\subsection{Unit Structure}

The unit consists of one or more hydraulic prop (legs), holding up the upper part of the unit (roofbar) and hydraulic shifting system, responsible for shifting the unit with the longwall advance simultaneously. Each unit should prop the roof with the demanded strength to assure the safety of mining. After each shearer passage the unit shifts and then props the newly bared rocks.

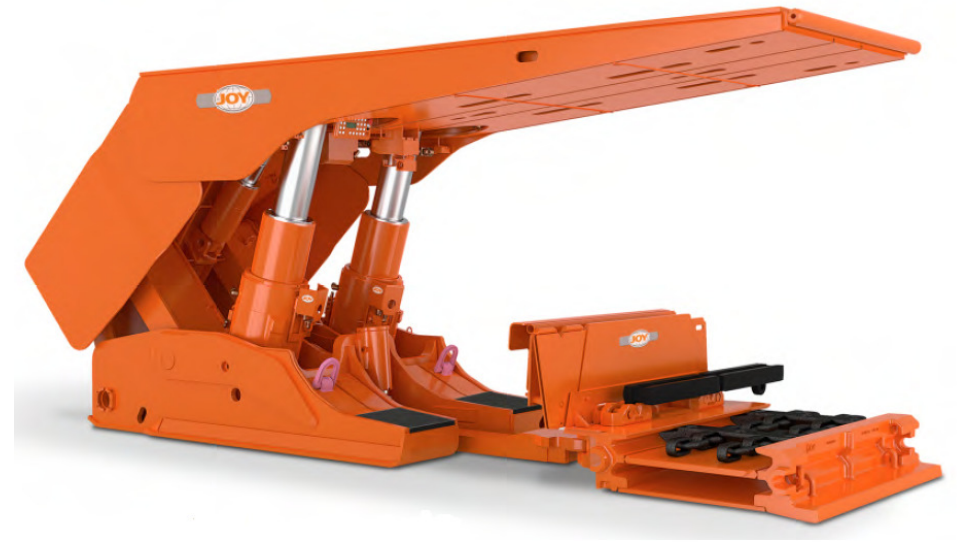

Fig. 3Single unit of powered roof support (www.joy.com).

\subsection{Working cycle}

Each unit of a powered roof support performs the same activities sequentially. Starting from the moment of the shearer passage a typical sequence of events can be defined. After a shearer passage there is a new roof unpropped. The hydraulic system decreases the pressure in the leg to break the contact with the roof. Then a shifting is performed. Afterwards a rapid pressure increase in the leg is performed to restore the contact with the roof. The pressing formation tries to compress the unit - to decrease its height - but the hydraulic system avoids it by the pressure 
increase in legs. It is visible as the slow and gradual pressure increase. Shortly before the next shearer passage a faster pressure increase can be observed as the effect of preceding units lack of roof contact.6000 second long leg pressure series is presented on the Fig. 4

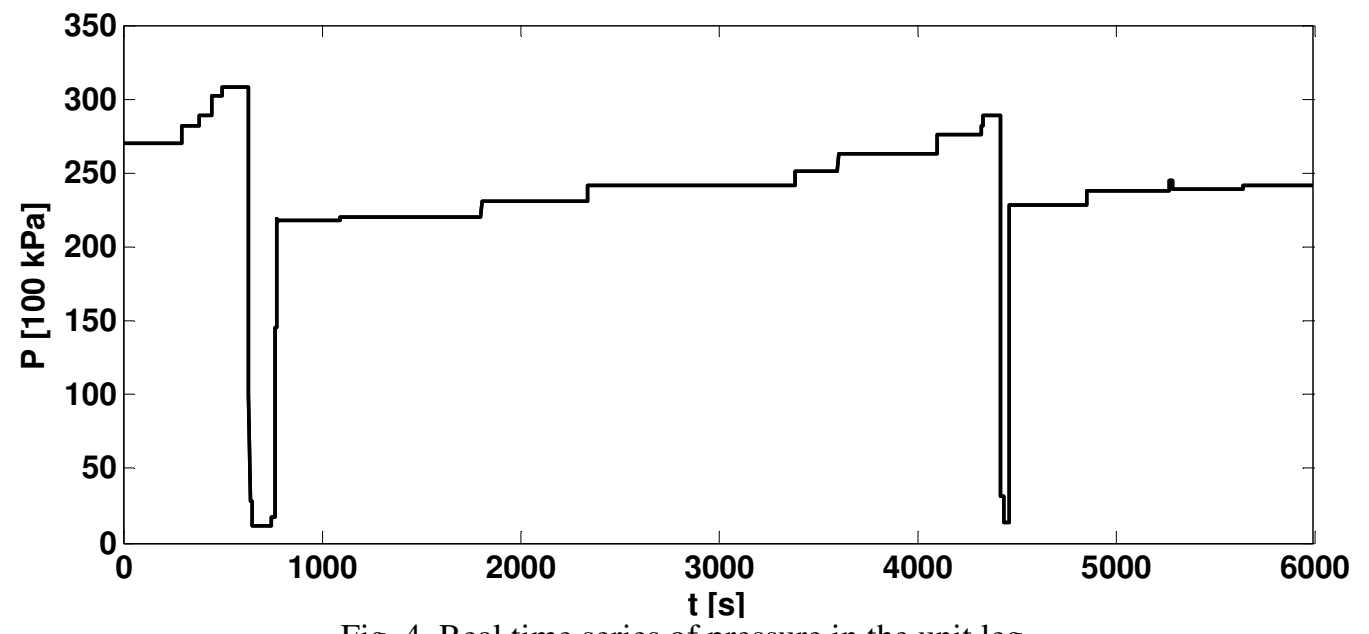

Fig. 4. Real time series of pressure in the unit leg.

The very short and fast pressure decrease can be observed between $635^{\text {th }}$ and $648^{\text {th }}$ second. The shifting is performed between $649^{\text {th }}$ and $751^{\text {st }}$ second. The initial pressure increase can be observed between the $752^{\text {nd }}$ and $772^{\text {nd }}$ second. The further slow pressure increase, caused by the formation pressure, is observed between $773^{\text {rd }}$ and $4000^{\text {th }}$ second. The last mentioned phase is observed between the $4000^{\text {th }}$ second and the $4400^{\text {th }}$ - the beginning of the next unit working cycle.

\section{RANDOMIZED MODEL OF A SINGLE UNIT WORK}

The gradual-randomized model, presented in this paper, is the extension of the mathematical (also randomized) model described in [8]. Its basics and the current extension will be presented in the following subsections.

\subsection{Working Cycle Decomposition}

For the purpose of unit operation modelling a single working cycle was divided into the following five phases, starting from the moment of a rapid leg pressure decrease:

- treading,

- spragging,

- overbuilding,

- pre-treading,

- pressure lowering.

\subsection{Randomized Phase Duration}

The previous model assumed a linear pressure change in the three first phases: very low during treading and overbuilding and quite high in the spragging. The model of pressure lowering was 
dual: rapid or gradual. For the purpose of pre-treading modelling one of four models was drawn. These models are described in Table 1 and presented on Fig. 5.

Table 1. Four pre-treading models equations.

\begin{tabular}{|l|c|}
\hline Model & Equation \\
\hline Linear & $y=x$ \\
\hline Squared & $y=x^{2}$ \\
\hline Exponential & $y=\exp (a(x-1))$ \\
\hline Arched & $y=1-\sqrt{1-x^{2}}$ \\
\hline
\end{tabular}

Also the duration of each phase was drawn from the range, prepared for each phase separately. The initial level of the pressure for the first modelled phase was also randomized, but starting from the second phase, the initial pressure value implied from the final pressure in the preceding one. Also the initial value of the pressure during the second treading implied from the final value of a first pressure lowering.

\subsection{Randomized Phase Dynamic}

All parameters of phases - especially slopes for linear sections - were drawn from the specified range but without taking into consideration the phase duration. It was clearly visible when the pressure value at the end of the spragging was considered. It was expected to obtain comparative values, due to the fact that usually propping the roof should start at specified level of the pressure. Inexactness of this approach is visible on the Fig. 7.

\section{GRADUAL-RANDOMIZED MODEL OF A SingLE UNIT WORK}

The presented model disadvantages led to its extension and modification. The modification consist in assuring more stable dynamic in the spragging phase. The extension of the model consist in particular discretization of a continuous pressure change characteristic into the interval one.

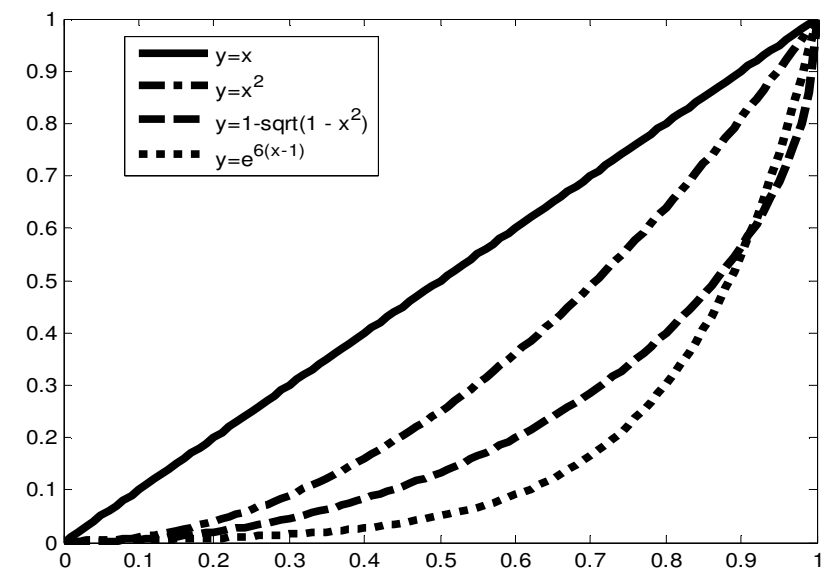

Fig. 5. Possible pressure increase characteristics in the pre-treading phase. 
A single realisation of modelling one single unit working cycle is presented on Fig. 6.

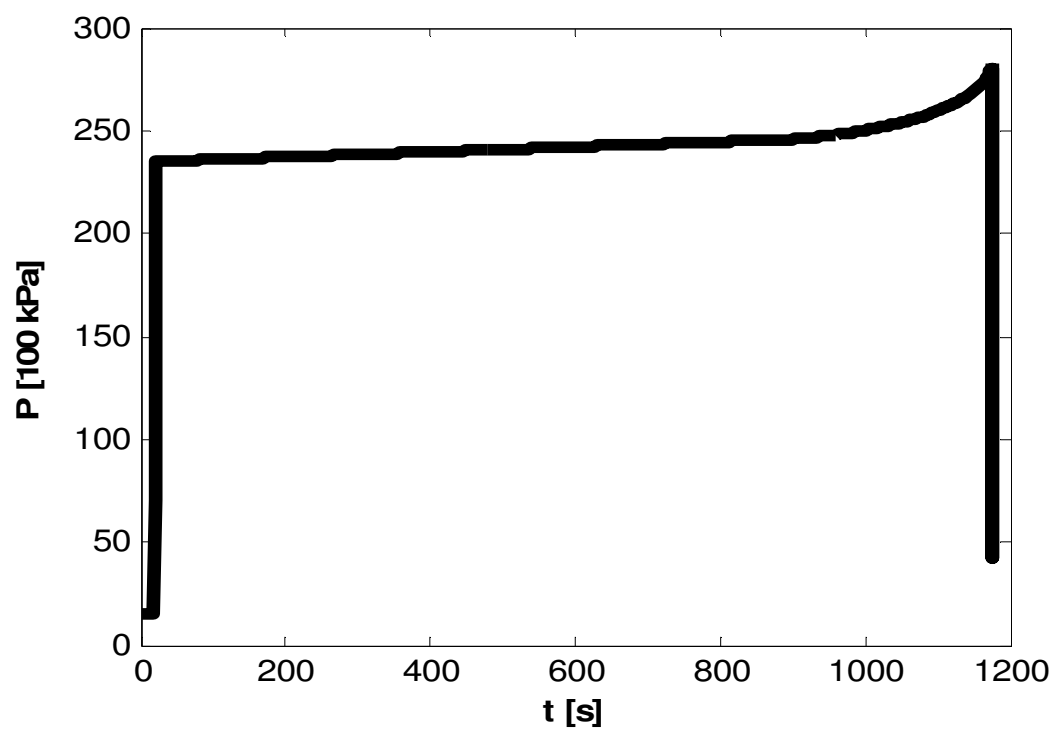

Fig. 6. A modelled single unit working cycle.

\subsection{Stable Spragging Dynamic}

In the previous approach duration of the phase and the dynamic of the linear pressure increase were drawn separately. As it led to improper results in some cases a modification was proposed: it binds the duration of spragging with its dynamic and the limited final value of a pressure after this phase. Instead of drawing a phase duration and phase dynamic separately, a phase duration and the final pressure are drawn. As the initial pressure is known, the phase dynamic is implied by the difference of the pressure values and the time interval.

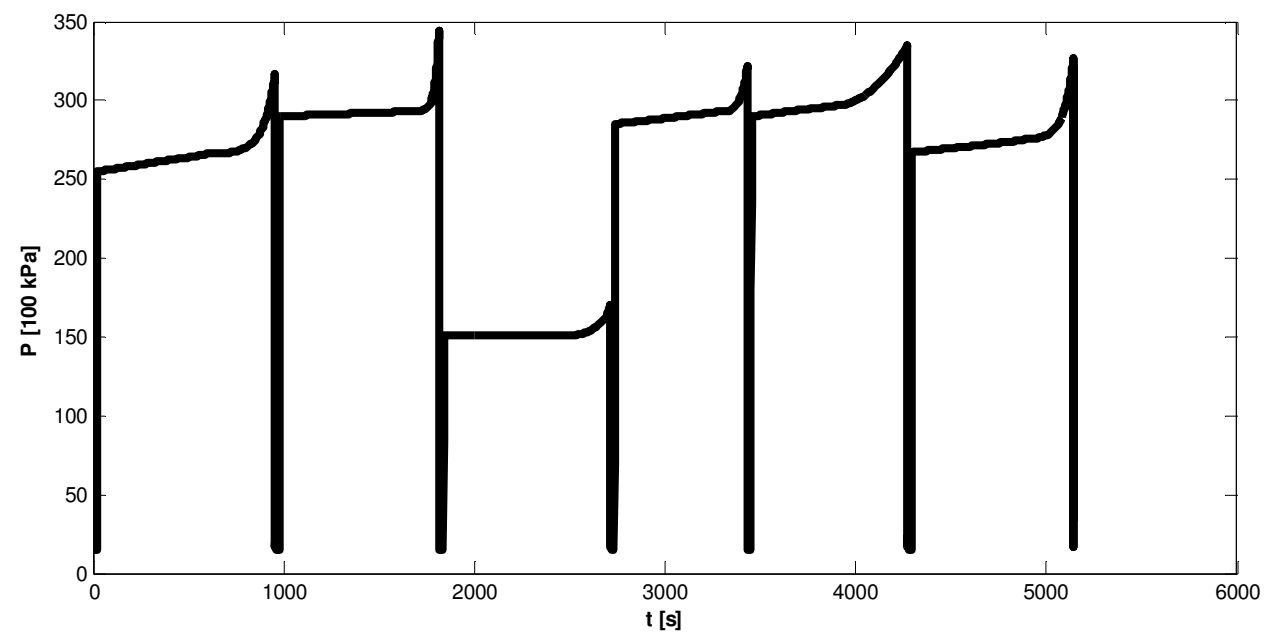

Fig. 7. A modelled several consecutive unit working cycles. 


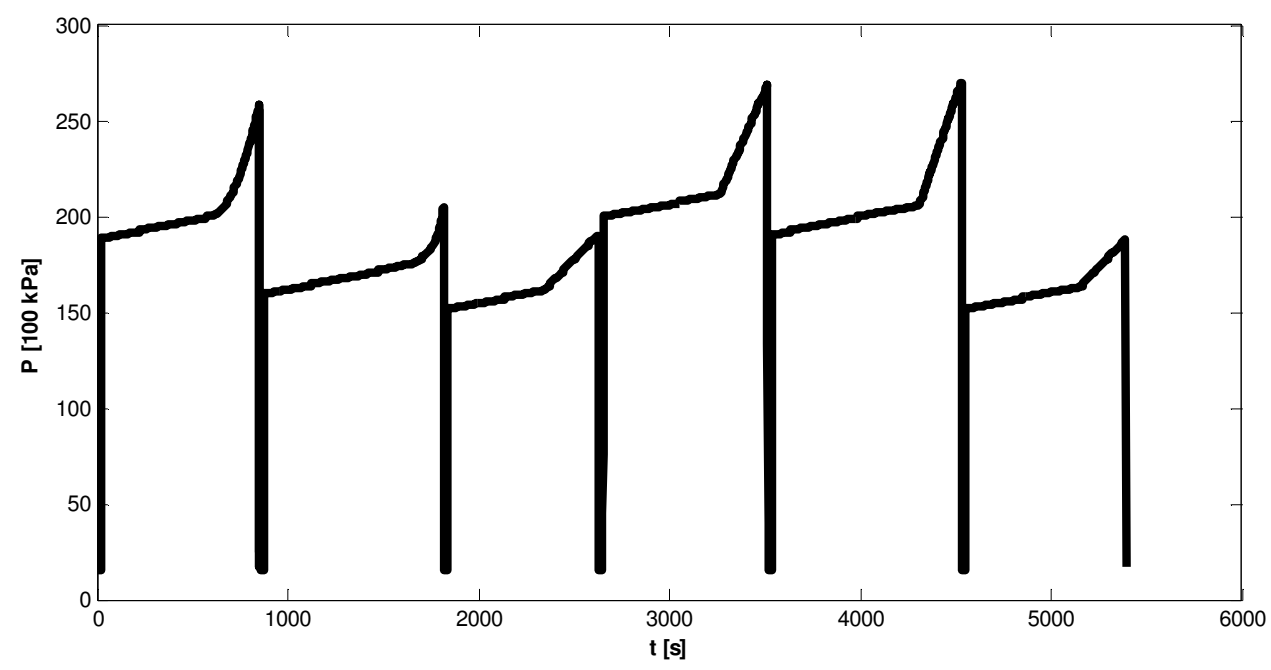

Fig. 8. A model of several consecutive unit working cycles with improved spragging dynamic.

The result of this modification becomes more apparent when histograms of spragging final values are compared: histogram for an original model and the new model with more stable spragging dynamic. These histograms are presented on Fig. 9.

\subsection{Gradual Pressure Increase}

As it was seen on Fig. 2 the pressure increase does not have a linear characteristic. Due to this fact the following discretization of an increase is proposed. The algorithm of discretization to the gradual pressure increase is also random. It splits the time range into the smaller ones and in every small range the pressure value remains unchanged.

Let us consider a sequence of $n$ points $\left(\left(x_{1}, y_{1}\right),\left(x_{2}, y_{2}\right), \ldots,\left(x_{n}, y_{n}\right)\right)$ which are nondecreasing due to the x's and y's:
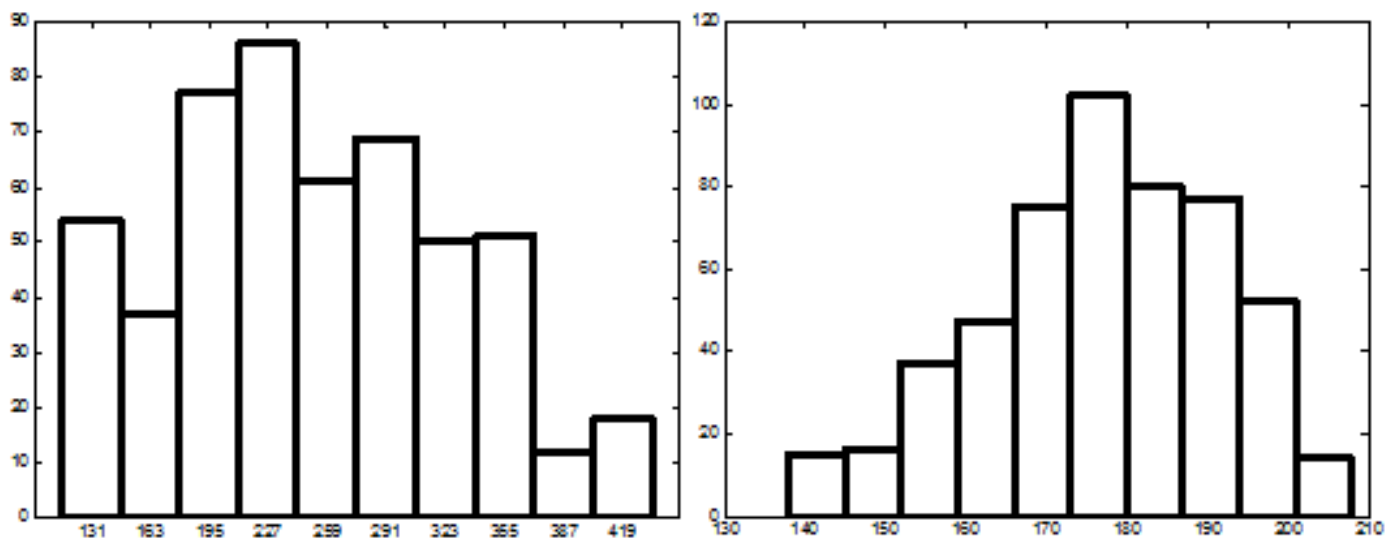

Fig. 9. Comparison of histograms of spragging final value in the original (left) and improved (right) model. 


$$
\forall i, j \in\{1,2, \ldots, n\} \quad i<j \Leftrightarrow x_{i} \leq x_{j} \wedge y_{i} \leq y_{j}
$$

that we expect to be discretized into $\mathrm{k}+1$ values. Then $\mathrm{k}$ random values $r_{1}, r_{2}, \ldots, r_{k}$ from the uniform range $[0,1]$. Then random values are scaled into the range of the number of points in the data:

$$
R_{m}=\left\lfloor\frac{r_{m}}{r_{k}} n\right\rfloor
$$

Now the scaled indexes are decreased (moved into the left on the axis) by the half of the left sided range. The moved index is the boundary between the smaller and the higher value of the discretized pressure. The upper boundaries take the following values:

$$
\left\{\begin{array}{c}
B_{1}=0.5 R_{1} \\
B_{i}=0.5\left(R_{i-1}-R_{i}\right) \quad 1<i \leq k
\end{array}\right.
$$

If we assume $B_{0}=x_{1}$ then we have $B_{k+1}=x_{k}$ then we have $k+1$ intervals. A discretized value of the function in the interval $\left(B_{i}, B_{i+1}\right)$ is the minimal value of the $\mathrm{y}$ for all $\mathrm{x}$ 's from this range.

The whole idea and the result are presented on the Fig. 8. A dotted line represents the original monotonic function. As X's - for better understanding placed on the line $y=-1$ - are cumulated values of indexes in the input data. Black dots - on the line $y=0.5-$ are centres of the ranges between x's and are also ends of ranges of a constant value of a discretized function.

\section{SAMPLE MODELS}

The following figures show several results of modelling of a set of 6 working cycles. As it can be observed, in comparison with the series on the Fig. 4 - a real series - and Fig.7 - the first simple model, new model generates more repeatable cycles. Repeatability means that following cycles reach comparable value of the pressure after spragging. The characteristic of a pressure increase after spragging - the overbuilding phase - is much more realistic as well.

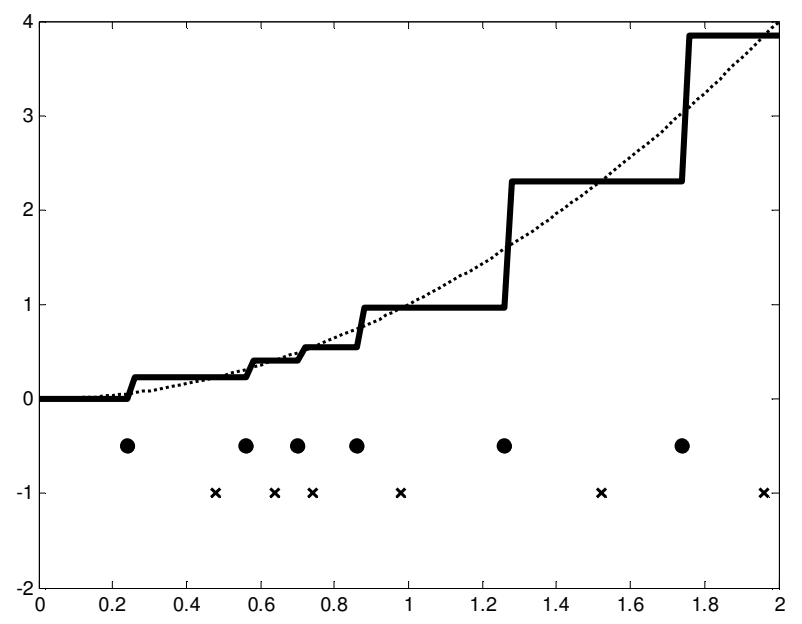

Fig. 10. A discretized series (solid line) on the background of the original one (dotted). 

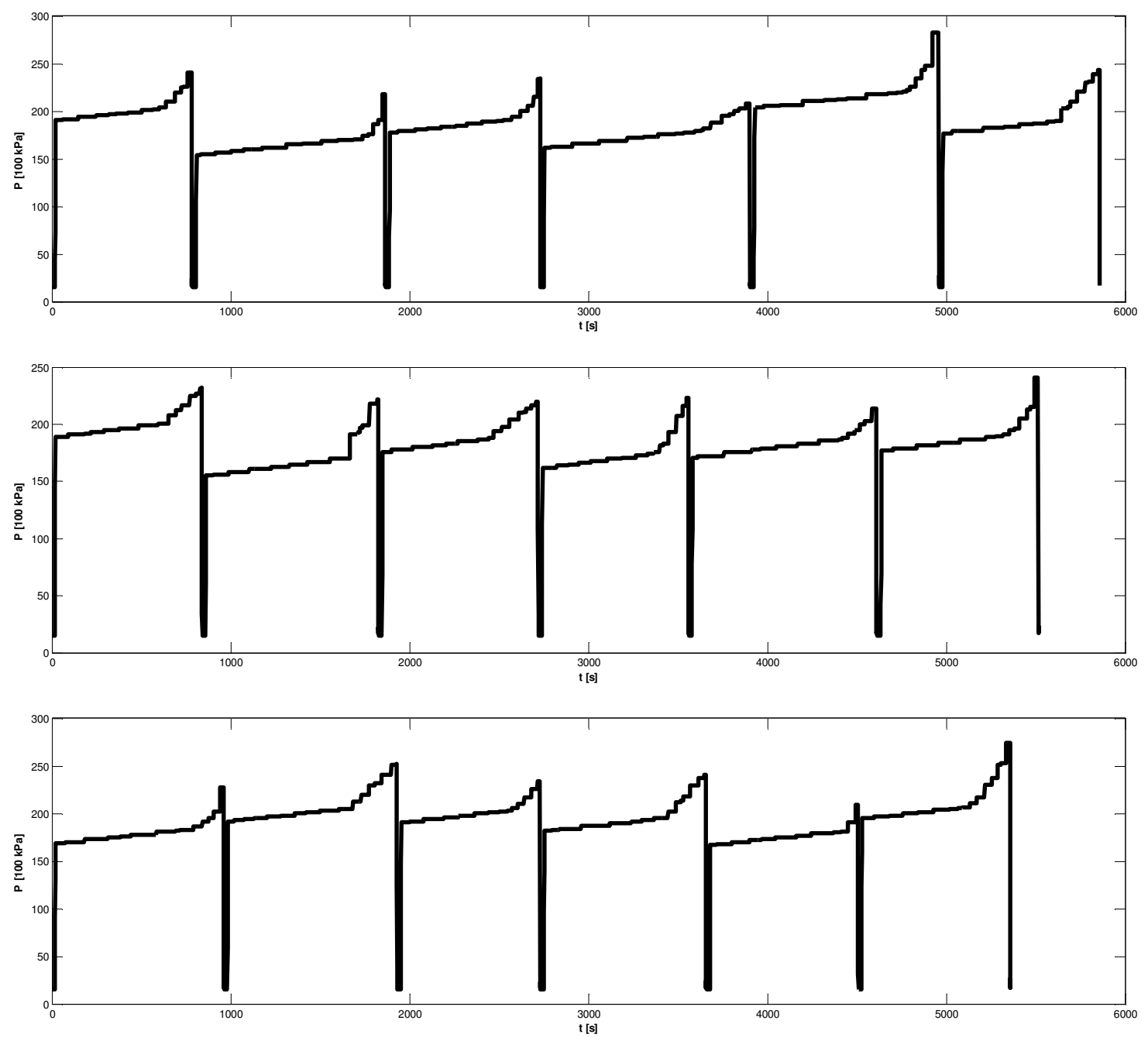

Fig. 11. A discretized series (solid line) on the background of the original one (dotted).

\section{CONCLUSIONS}

Building a diagnostic models and software requires a lot of data from the monitored device. This is particularly difficult to obtain the data, containing patterns of various ways of operating, including also faults and human mistakes, from complicated complexes. The process of delivering a reliable data generator simplifies and accelerates building up diagnostic models as it allows analysis even very sophisticated deviation of the proper machine operation. In this paper the improved model of building a model of a single powered roof support unit was presented. This model reflects all typical phases of the correct work of the device, assures a stability of steady value after spragging and gives more realistic characteristic of a gradual pressure increase.

In its current form the model does not include many aspects of real disturbances, just to mention the most important ones as leakage of the hydraulic liquid, correlation between two (three) legs of the same unit, influence of the other units work phases, shearer localisation. Further works will focus on including mentioned elements in the model progressively. 


\section{ACKNOWLEDGEMENTS}

This work was supported by the European Union from the European Social Fund (grant agreement number: UDA-POKL.04.01.01-106/09).

\section{REFERENCES}

[1] Statystyka elektroenergetyki polskiej (in Polish), ARE annual report

[2] International Energy Agency Report, http://www.iea.org/statistics/statisticssearch/report/?year=2012\&country=GERMANY\&product=Elec tricityandHeat

[3] Bartelmus W.: Condition Monitoring of Open Cast Mining Machinery.Wroclaw University of Technology Press, Wroclaw 2006.

[4] Gąsior S.: Diagnosis of Longwall Chain Conveyor. Mining Review, Vol. 57, No. 7-8, pp. 33-36, 2001.

[5] Kacprzak M., Kulinowski P, Wędrychowicz D.: ComputerizedInformation System Used for Management of Mining Belt ConveyorsOperation., Eksploatacja i Niezawodnosc - Maintenance and Reliability,Vol. 13, No. 2, pp. 81-93, 2011.

[6] Michalak M., Sikora M.: Analiza pracy silników przenośników ścianowych - propozycje raportów i wizualizacji” (in Polish), Mechanizacja i Automatyzacja Górnictwa, Vol. 436, No. 5, pp. 17-26, 2007.

[7] Michalak M., Sikora M., Sobczyk J.: Analysis of the Longwall ConveyorChain Based on a Harmonic Analysis", Eksploatacja i Niezawodnosc- Maintenance and Reliability, Vol. 15, No. 4, pp. 332-336, 2013.

[8] Michalak M.: Modelling of Powered Roof Supports Work.International Journal of Computer, Information Science and Engineering, 2015 (to appear)

\section{AUTHOR}

Marcin Michalak Marcin Michalak was born inPoland in 1981. He received his M.Sc. Eng. Incomputer science from the Silesian University of Technology in 2005 and Ph.D. degree in 2009 from the same university. His scientific interests are in machine learning, data mining, rough sets and biclustering. He is an author and coauthor of over 60 scientific papers.

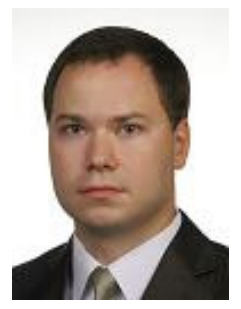

